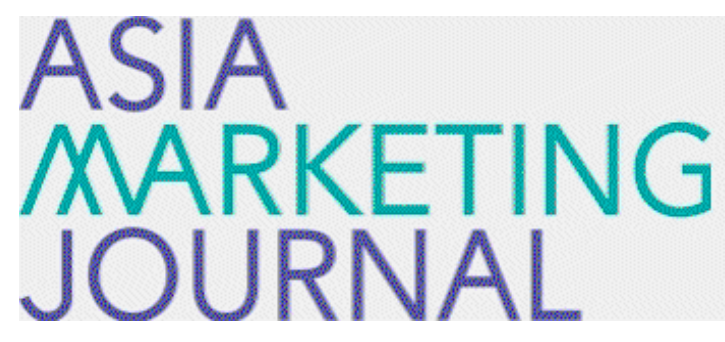

ASIA MARKETING JOURNAL

Volume 19 | Issue 4

Article 3

$1-31-2018$

\title{
Effects of Channel Structure on the Quality Competition of Exclusively Distributed Products
}

Yeong Seon Kang

Follow this and additional works at: https://amj.kma.re.kr/journal

Part of the Marketing Commons

\section{Recommended Citation}

Kang, Yeong Seon (2018) "Effects of Channel Structure on the Quality Competition of Exclusively Distributed Products," Asia Marketing Journal: Vol. 19 : Iss. 4 , Article 3.

Available at: https://doi.org/10.15830/amj.2018.19.4.37

This Article is brought to you for free and open access by Asia Marketing Journal. It has been accepted for inclusion in Asia Marketing Journal by an authorized editor of Asia Marketing Journal. 


\title{
Effects of Channel Structure on the Quality Competition of Exclusively Distributed Products*
}

\author{
Yeong Seon Kang**
}

\begin{abstract}
This study investigates the effects of the distribution channel structure on quality decisions under duopoly competition. I considers a set-up in which two retailers compete on product quality and retail price. In the set-up, the integrated retailer has the power to determine the quality of its exclusive product, while the decentralized retailer does not. For the decentralized retailer, the supplier determines product quality. I find that asymmetric pairs of a decentralized channel by one retailer and an integrated channel by the other retailer can be a Nash equilibrium in a simultaneouschannel-choice model. The two retailers select different levels of quality, and this quality competition benefits retailers by softening price competition. In a sequential-channel-choice model, I find that the leader can obtain a first-mover advantage. From the perspective of the supplier, which can decide the distribution channel structure and level of quality, both suppliers choose the decentralized channel in equilibrium.
\end{abstract}

Key words: Product Quality, Distribution Channel, Horizontal Differentiation, Game Theory

\section{Introduction}

Today, many retailers exclusively sell specific brands (either store/private brands or other exclusive brands) in their own stores to various degrees of success. Owing to the long-term global recession, these exclusive brands have been continuously released in the market. When we consider private brand products, the industry and market have focused on price competition based on relatively low quality and low price. Recently, however, retailers have introduced exclusively distributed products with improved quality in order to increase store traffic and enhance the retailer's brand image (Gielens et

\footnotetext{
* This work was supported by the Ministry of Education of the Republic of Korea and the National Research Foundation of Korea (NRF-2016S1A5A8017679).

** Assistant Professor Department of Business Administration University of Seoul (yskang2014@uos.ac.kr)
} 
al. 2014).

These exclusive products for a specific retailer can help it attract more customer traffic to the store and strengthen customer loyalty (Corstjens and Lal 2000). For example, BestBuy, the largest electronics retailer in the world, is considering expanding its exclusive product line to reinvent its brand and improve profitability (Burritt 2012). Steenkamp and Dekimpe (1997) show that a consumer loyal to an exclusive store brand is more likely to be loyal to that store. Binninger (2008) also shows that a consumer's loyalty to an exclusive product in a particular store is positively related to his or her loyalty to the store. Hence, exclusive products may contribute to the store's ability to differentiate itself (Bonfrer et al. 2004; Collins-Dodd and Lindley 2003). On the contrary, when retailers' strategies focus on low price/low quality to target price-sensitive consumers, this can have a negative impact on a consumer's store loyalty (Gielens et al. 2014; Peres and Van den Bulte 2014). Product quality is one of the most significant attributes of the purchase/repurchase decision for building consumer loyalty (Raju, Srinivasan, and Lal 1990; Aaker 1993). The quality of an exclusive product might thus be the key factor to achieving loyalty, and a higher level of quality might enhance a customer's store loyalty. Some empirical research (Ailawadi et al. 2008; Gonzales-Benito and Martos-Partal 2012) finds a relationship between a consumer's store loyalty and product evaluation. When consumers have strong loyalty to retailers, they provide a relatively positive evaluation of store brand products.

This study uses analytical modeling to investigate the consumer's store loyalty and product quality of exclusively distributed products as key variables from the perspective of retailers. My research starts from the question of who controls the quality of the exclusive products that retailers carry in their stores. For example, in one case, the retailer may control product quality, while in another, an upstream supplier may be an independent strategic player controlling product quality and setting wholesale prices for the retailer. The level of quality may thus depend on who makes the decision. I investigate how the distribution channel structure affects the level of quality decision and how the level of quality affects the consumer's decision given his or her loyalty to a retailer. From this perspective, this study examines the effects of the distribution channel structure on quality decisions, considering competition at both the retailer and the supplier levels.

While the analytical modeling literature refers to quality differentiation as vertical differentiation, I incorporate quality differentiation with a quality weight on the consumer's loyalty to a retailer in a consumer's utility function for a product bought from that retailer. For example, Trader Joe's, a grocery store chain in the United States, is gaining popularity among consumers 
looking for healthy and/or organic foods at affordable prices. Charles Shaw wine, exclusively distributed by Trader Joe's, is rated as excellent quality at an affordable price ( $\$ 1.99-\$ 2.99$ / bottle). Consumers' perceived quality towards Charles Shaw wine could be influenced by their loyalty to the distributor, Trader Joe's. If a consumer has strong loyalty to Trader Joe's, he or she may perceive one of its products as being of higher quality compared with the actual quality (Cholette 2004). Perceived quality can be assumed by consumers' subjective evaluations based on their store loyalty.

This study is related to the literature on distribution channel selection. The issues associated with optimal channel selection have been explored extensively. In a monopoly case, vertical integration is optimal, because the decentralized channel has the double marginalization problem. In a duopoly case, several researchers have studied optimal channel selection between vertical integration and decentralization (McGuire and Staelin 1983; Moorthy 1988; Coughlan 1985; Coughlan and Wernerfelt 1989; Trivedi 1998; Liu and Tyagi 2009; Zhao, Atkins, and Liu 2009).

McGuire and Staelin (1983) compare three types of channel structures: vertically integrated, decentralized, and mixed (in which one manufacturer distributes products through a private retailer and the other manufacturer distributes products through its own stores). They introduce competition as one of the reasons why decentralization may be optimal under relatively high competition at the product level. They find that the optimal channel depends on product substitutability and explain that decentralization has a "buffer effect" on competition. Moorthy (1988) shows that the necessary condition for decentralization to be a Nash equilibrium strategy is a function of the effect of strategic interaction on a manufacturer's channel structure decision. He finds that decentralization is a Nash equilibrium strategy if the manufacturer's products are demand substitutes and strategic complements at the manufacturer or retailer level or if the manufacturer's products are demand complements and strategic substitutes at the manufacturer or retailer level. Coughlan and Wernerfelt (1989) show that decentralization gives a manufacturer the ability to become a Stackelberg leader in the channel, which drives decentralization to be optimal. Trivedi (1998) compares three channel mechanisms: the vertically integrated channel, the decentralized channel, and the fully symmetric channel. She shows that the fully symmetric channel is always superior to the decentralized channel, considering the competition between stores and products.

Liu and Tyagi (2009) also show how downstream firms can benefit from upward channel decentralization when their product positioning is endogenous. When product positioning is endogenous, upward channel decentralization induces more differentiation between firms. As 
a result, price competition at the downstream level is softened and downstream firms can achieve higher profits. While Liu and Tyagi (2009) show how decentralization can reach equilibrium under horizontal differentiation and endogenous product positioning, Zhao et al. (2009) examine the impact of channel structure under vertical differentiation and endogenous quality positioning. They assume that two firms are vertically differentiated (i.e., a highquality firm vs. a low-quality firm). Changes in channel structure have asymmetric effects on the firm's original quality positioning. While the product quality of the high-quality firm decreases when it decentralizes, the product quality of the low-quality firm increases when it decentralizes. They find that because the benefit of differentiating one's product from that of the competitor is greater than the benefit of adopting a decentralized channel, decentralization cannot be sustained in qualitydifferentiated and endogenous quality positioning.

I consider a set-up in which two retailers compete on quality and retail price. A retailer can adopt either an integrated channel structure in which it functions as the manufacturer or a decentralized channel structure in which an upstream supplier produces the product for the retailer. The integrated retailer has the power to determine its product quality, while the decentralized retailer does not. For the decentralized retailer, the supplier determines product quality and wholesale price. In this study, I attempt to answer the following questions: (1) Does a distribution channel structure play a role in this product quality decision? (2) Should the product quality of the two retailers with asymmetric distribution channel structures differ? (3) When and how does a retailer benefit from decentralization in a set-up in which I consider the interaction effect between a consumer's loyalty and the level of product quality? (4) When I consider that retailers choose their distribution channel structure sequentially instead of simultaneously, does a first-mover advantage exist? (5) When I consider a set-up in which suppliers make the quality decision instead of retailers, how does it affect the equilibrium outcome of the distribution channel structure?

I find that asymmetric pairs of a decentralized channel by one retailer and an integrated channel by the other retailer can be Nash equilibria in the simultaneous-channel-choice model. When the market is covered and competition between retailers exists, the two retailers choose asymmetric pairs of distribution channel structures and given this asymmetric channel, they choose different levels of quality. Therefore, this quality competition benefits retailers by softening price competition. However, this result cannot be sustained if a retailer plays the role of a local monopolist. When the market is not covered, both retailers in equilibrium choose the integrated channel because of the double marginalization problem (McGuire and 
Staelin 1983; Moorthy 1988). Specifically, in a sequential-channel-choice model, I find that when the market is covered, the leader-retailer chooses the integrated channel and the followerretailer chooses the decentralized channel, meaning that the leader can obtain a firstmover advantage. Changing to the supplier's perspective to decide the distribution channel structure and level of quality, the results are different from the perspective of retailers. While asymmetric pairs of distribution channel structures can reach the equilibrium outcomes from the retailer's perspective, symmetric pairs of distribution channel structures are the equilibrium outcomes from the perspective of suppliers. When the market is covered and competition between the channels exists, both suppliers choose the decentralized channel in equilibrium. When the market is not covered and each channel plays the role of a local monopolist, both suppliers choose the integrated channel in equilibrium.

\section{The Model}

Consider a market with two retailers $(i=$ $A, B)$ selling a product with quality $q_{i}$ $\left(q_{i}>0 ; i=A, B\right)$, respectively. These retailers choose the channel distribution structures and then the strategic variables depending on the channel distribution structures selected in the previous stage. I consider both the simultaneous and the sequential moves of the retailers. In the simultaneous-channel-choice model, the two retailers choose the distribution channel structure simultaneously. In the sequentialchannel-choice model, one retailer chooses its distribution channel structure before the other retailer. The model assumptions are described below.

\subsection{Retailers}

I assume that the two retailers, $\mathrm{A}$ and $\mathrm{B}$, are located at 0 and 1 along the unit line in the interval $[0,1]$, respectively. The marginal production cost of quality is assumed to be $c\left(q_{i}\right)=q_{i}^{2}$. I assume that products of a higher level of quality are costlier to produce. Either upstream suppliers produce products for the retailer, which are integrated (integrated, denoted by I), or the retailer operates independently (decentralized, denoted by D). The distribution channel structure II denotes when the two retailers are integrated, DD when the two retailers are decentralized, and ID for competition between the integrated and decentralized channels. When integrated, retailer $i(i=A, B)$ sets its own level of quality. When decentralized, supplier $i$ sets the level of quality and wholesale price, and retailer $i$ purchases from supplier $i$ at wholesale price $w_{i}$. 


\subsection{Consumers}

I assume that consumers are distributed uniformly along the unit line in the interval $[0$, 1] and the total number of consumers is normalized to 1 . Consumers have relative loyalty to each retailer $(y)$. The level of quality, $q_{i}\left(q_{i}>0 ; i=A, B\right)$, plays the role of a weight on the loyalty to each retailer.

Net utility for a consumer located at $y$ from purchasing Retailer A's product is $U_{A}=\nu+$ $q_{A}(1-y)-p_{A}$. For Retailer B's product, net utility is $U_{B=\nu}+q_{B} y-p_{B}$. I assume that $\nu$ is a reservation value and $p_{i}(i=A, B)$ is the retail price of each retailer's product. $q_{i} y$ represents the consumer's utility based on relative loyalty and each retailer's level of quality.

Consumers have perfect information about the levels of quality and prices. If they decide to buy, they buy one unit of the product that provides the highest utility. If the utility obtainable from the two retailers is less than zero, then they will buy the outside good and the consumer's utility from the outside good is assumed to be zero.

Intuitively, if I assume that a consumer is located at $y=0$, then the net utility that the consumer receives from buying a product from Retailer $\mathrm{A}$ is $\nu+q_{A}-p_{A}$, while the net utility that the consumer receives from buying a product from Retailer B is $\nu-p_{B}$. Similarly, for a consumer located at $y=0.2$, the net utility that the consumer receives from buying a product from Retailer $\mathrm{A}$ is $\nu+0.8 q_{A}-p_{A}$, while the net utility that the consumer receives from buying a product from Retailer $B$ is $\nu+0.2 q_{B}-p_{B}$. A consumer located at $y=0.2$ has relatively strong loyalty to Retailer $\mathrm{A}$ and his or her utility is positively related to his or her loyalty as well as weighted by each retailer's level of quality. As the retailer's level of quality rises, the consumer's utility increases; however, this increase depends on his or her relative loyalty to Retailers A and B.

\subsection{Sequence of the Game}

In the simultaneous-channel-choice model presented in Section 3, the sequence of the game is as follows. First, the retailers set the distribution channel structure. They decide whether to integrate or decentralize their upstream supplier. Second, either the retailer with the integrated channel or the supplier with the decentralized channel chooses the product quality level. Third, the suppliers (in the case of decentralized channels) set wholesale prices $w_{i}$. Fourth, the retailers simultaneously set retail prices $p_{i}$. Fifth, consumers decide which products to purchase.

By contrast, in Section 5, I consider the sequential-channel-choice model, in which the leader-retailer chooses the distribution channel 
structure before the other retailer. The follower chooses the distribution channel structure after it observes the leader's distribution channel structure. Second, either the retailer with the integrated channel or the supplier with the decentralized channel chooses the product quality level. Third, the suppliers (in the case of decentralized channels) set wholesale prices $w_{i}$. Fourth, the retailers simultaneously set retail prices $p_{i}$. Fifth, consumers decide which products to purchase.

\section{Simultaneous Move Game: Market Is Covered}

I use backward induction to solve the subgame perfect equilibrium for prices and levels of quality. I assume that the consumer's reservation value, $\nu$, is sufficiently large so that all consumers buy one of the two products and the market is covered.

To calculate the demand function, I derive the indifference point at which the marginal consumer is indifferent between the two retailers. The indifference point is given by

$$
\bar{y}=\frac{q_{A}-p_{A}+p_{B}}{q_{A}+q_{B}} .
$$

Let $D_{A}$ and $D_{B}$ denote the range of demand for the products of Retailers A and B, respectively. All consumers between zero and the marginal consumer buy from Retailer A, whereas all consumers between the marginal consumer and 1 buy from Retailer B.

\subsection{Quality Decision under the Integrated vs. Integrated Channel Structure}

I first study the case in which both the retailers produce their own products. Let $\pi_{A}$ and $\pi_{B}$ represent the profits of Retailers A and $\mathrm{B}$, respectively:

$$
\pi_{i}=\left(p_{i}-q_{i}^{2}\right) D_{i} ;(i=A, B)
$$

The retailers choose their retail prices to maximize profits, taking the equilibrium levels of quality as given. Solving the first-order conditions of profit maximization gives the following price reaction functions:

$$
\begin{aligned}
& \bar{p}_{A}=\frac{1}{3}\left(2 q_{A}^{2}+2 q_{A}+q_{B}^{2}+q_{B}\right), \\
& \bar{p}_{B}=\frac{1}{3}\left(2 q_{B}^{2}+2 q_{B}+q_{A}^{2}+q_{A}\right) .
\end{aligned}
$$

I substitute the price reaction functions into the profit functions and then Retailers $\mathrm{A}$ and $B$ choose the level of quality to maximize profits. The equilibrium levels of quality are obtained by solving the first-order conditions simultaneously.

I find the following optimal level of quality, retail prices, and retailers' profits: 


$$
\begin{aligned}
& q_{A}^{*}=q_{B}^{*}=\frac{5}{8}, P_{A}^{*}=P_{B}^{*}=\frac{65}{64}, \\
& \pi_{A}^{*}=\pi_{B}^{*}=\frac{5}{16} .
\end{aligned}
$$

\subsection{Quality Decision under the Decentralized vs. Decentralized Channel Structure}

I now consider the case in which both the retailers choose the decentralized channel. Each decentralized supplier chooses its level of quality and then its wholesale price to maximize its profits. Each retailer chooses the retail price that maximizes its profits given the levels of quality and wholesale prices. In this model, the suppliers are Stackelberg leaders. Let $\pi_{A}$ and $\pi_{B}$ represent the profits of Retailers $\mathrm{A}$ and $\mathrm{B}$, and $\pi_{S A}$ and $\pi_{S B}$ represent the profits of Suppliers A and B, respectively:

$$
\begin{aligned}
& \pi_{i}=\left(p_{i}-w_{i}\right) D_{i}, \\
& \pi_{s i}=\left(w_{i}-q_{i}^{2}\right) D_{i} ;(i=A, B) .
\end{aligned}
$$

The retailers choose their retail prices to maximize profits, taking the equilibrium wholesale prices and levels of quality as given. Solving the first-order conditions of profit maximization gives the following price reaction functions:

$$
\begin{aligned}
& \bar{p}_{A}=\frac{1}{3}\left(2 q_{A}+q_{B}+2 w_{A}+w_{B}\right), \\
& \bar{p}_{B}=\frac{1}{3}\left(q_{A}+2 q_{B}+w_{A}+2 w_{B}\right) .
\end{aligned}
$$

I substitute the price reaction functions into the supplier's profit functions and then Suppliers $A$ and $B$ choose the wholesale prices to maximize profits. Solving the first-order conditions of the supplier's profit maximization gives the following wholesale price reaction functions:

$$
\begin{aligned}
& \bar{w}_{A}=\frac{1}{3}\left(2 q_{A}^{2}+5 q_{A}+q_{B}^{2}+4 q_{B}\right), \\
& \bar{w}_{B}=\frac{1}{3}\left(q_{A}^{2}+4 q_{A}+2 q_{B}^{2}+5 q_{B}\right) .
\end{aligned}
$$

By substituting the wholesale price reaction functions into the supplier's profit functions, I calculate the first-order conditions to maximize the supplier's profit functions with respect to the level of quality. Equilibrium levels of quality are obtained by solving the first-order conditions simultaneously.

I find the following optimal levels of quality, wholesale prices, retail prices, suppliers' profits, and retailers' profits:

$$
\begin{aligned}
& q_{A}^{*}=q_{B}^{*}=\frac{11}{8}, w_{A}^{*}=w_{B}^{*}=\frac{385}{64}, \\
& P_{A}^{*}=P_{B}^{*}=\frac{473}{64}, \\
& \pi_{S A}^{*}=\pi_{S B}^{*}=\frac{33}{16}, \pi_{A}^{*}=\pi_{B}^{*}=\frac{11}{16} .
\end{aligned}
$$

\subsection{Quality Decision under the Integrated vs. Decentralized Channel Structure}

Without loss of generality, I assume that 
Retailer A chooses the integrated channel and Retailer B chooses the decentralized channel. The integrated retailer sets its retail price to maximize its profit given the level of quality. Let $\pi_{A}$ represent the profit of Retailer $\mathrm{A}$ :

$$
\pi_{A}=\left(p_{A}-q_{A}^{2}\right) D_{A} .
$$

Decentralized Retailer B sets its retail price to maximize its profit given the level of quality and its wholesale price. Decentralized Supplier B chooses its level of quality and then sets its wholesale price to maximize its profit. Let $\pi_{B}$ and $\pi_{S B}$ represent the profits of Retailer $\mathrm{B}$ and Supplier B, respectively:

$$
\begin{aligned}
& \pi_{B}=\left(p_{B}-w_{B}\right) D_{B}, \\
& \pi_{S B}=\left(w_{B}-q_{B}^{2}\right) D_{B} .
\end{aligned}
$$

Solving the first-order conditions of the retailers' profit maximization gives the following price reaction functions:

$$
\begin{aligned}
& \bar{p}_{A}=\frac{1}{3}\left(2 q_{A}^{2}+2 q_{A}+q_{B}+w_{B}\right), \\
& \bar{p}_{B}=\frac{1}{3}\left(q_{A}^{2}+q_{A}+2 q_{B}+2 w_{B}\right) .
\end{aligned}
$$

I substitute the price reaction functions into Supplier B's profit function and then Supplier $\mathrm{B}$ chooses the wholesale price to maximize profits. Solving the first-order conditions for Supplier B's profit maximization gives the following wholesale price reaction function:

$$
\bar{w}_{A}=\frac{1}{2}\left(q_{A}^{2}+q_{A}+q_{B}^{2}+2 q_{B}\right) .
$$

By substituting the retail price reaction function into Retailer A's profit function and substituting the wholesale price reaction function into Supplier B's profit function, I calculate the first-order conditions to maximize the profit functions of Retailer A and Supplier B with respect to the level of quality. The equilibrium levels of quality are obtained by solving the first-order conditions simultaneously.

I find the following optimal levels of quality, wholesale prices, retail prices, suppliers' profits, and retailers' profits:

$$
\begin{aligned}
& q_{A}^{*}=\frac{8}{5}, q_{B}^{*}=\frac{2}{5}, w_{B}^{*}=\frac{64}{25}, \\
& p_{A}^{*}=\frac{94}{25}, p_{B}^{*}=\frac{84}{25}, \\
& \pi_{A}^{*}=\frac{18}{25}, \pi_{B}^{*}=\frac{8}{25}, \pi_{S B}^{*}=\frac{24}{25} .
\end{aligned}
$$

\subsection{Equilibrium Outcomes and Comparisons}

By using the results presented in the previous sections, I compare the equilibrium results for quality, price, and profit. The outcomes for the levels of quality, retail prices, and retailers' profits under the three distribution channel structures are summarized in Table 1.

Consumers are better off in the integrated channel than in the decentralized channel. As shown in Table 1, the channel structure of II 
〈Table 1〉 Outcomes of Quality, Retail Prices, and Retailers' Profits under the Three Distribution Channel Structures in the Simultaneous-Channel-Choice Model

(when the market is covered, $\nu$ is sufficiently large)

\begin{tabular}{ccccc}
\hline Channel Structure & II & DD & ID & D \\
\hline Quality & $\frac{5}{8}$ & $\frac{11}{8}$ & $\frac{8}{5}$ & $\frac{2}{5}$ \\
Retail Price & $\frac{65}{64}$ & $\frac{473}{64}$ & $\frac{94}{25}$ & $\frac{84}{25}$ \\
Profit & $\frac{5}{16}$ & $\frac{11}{16}$ & $\frac{18}{25}$ & $\frac{8}{25}$ \\
\hline
\end{tabular}

has the lowest retail price. If the channel is decentralized, its price increases because of the double marginalization problem. Decentralization leads to higher retail prices for consumers. Since the market is covered, each retailer has half of the market share under the symmetric condition. Because the two retailers have much higher retail prices under DD, they have higher profits under DD than under II.

Under the channel structure of ID, the integrated retailer can charge a higher retail price than the decentralized retailer as it offers a higher level of quality and thus is attractive to quality-sensitive consumers. Under this condition, the decentralized retailer offers a lower level of quality and a lower retail price. By doing so, it focuses on quality-insensitive and price-sensitive consumers.

Proposition 1 summarizes the equilibrium outcome for the channel structure decision in the simultaneous-channel-choice model under the condition of the market being covered.

\section{Proposition 1}

(simultaneous-channel-choice model) :

When the consumer's reservation value, $\nu$, is sufficiently large so that the market is covered, there are two pure-strategy Nash equilibria. In a pure-strategy Nash equilibrium, one retailer chooses the integrated channel and the other retailer chooses the decentralized channel, or vice versa.

Surprisingly, I find that decentralization does not always reduce the retailer's profit and that an asymmetric channel structure can reach equilibrium. The two retailers choose an asymmetric strategy in a pure-strategy equilibrium. If one retailer chooses the integrated channel, then the other retailer prefers the decentralized channel in equilibrium. Given this asymmetric channel structure, the two retailers choose different levels of quality, and quality competition benefits these retailers by softening price competition. Channel decentralization can thus 
lead to more quality differentiation, which can soften price competition.

\section{Simultaneous Move Game: Market Is Not Covered}

In the previous section, I computed the market-covered equilibrium for the simultaneouschannel-choice model. In this section, I compute the equilibrium when the market is not covered and the two retailers choose their distribution channel structures simultaneously. In this case, the two retailers act as local monopolists and some markets are not covered by either retailer. I use backward induction to solve the subgame perfect equilibrium for prices and levels of quality.

To derive the demand function, I calculate the boundary of Retailer A's market demand in which a consumer is indifferent between Retailer A's product and an outside good:

$$
\bar{y}_{A}=\frac{\nu+q_{A}-p A}{q_{A}} .
$$

Similarly, the boundary of Retailer B's market demand, in which a consumer is indifferent between Retailer B's product and an outside good, is

$$
\bar{y}_{B}=\frac{p_{B}-\nu}{q_{B}} .
$$

All consumers between zero and $\bar{y}_{A}$ buy from Retailer $\mathrm{A}$, whereas all consumers between $\bar{y}_{B}$ and 1 buy from Retailer B. Consumers between $\bar{y}_{A}$ and $\bar{y}_{B}$ buy an outside good, from which their utility is zero. To ensure meaningful results, the following assumption is necessary:

$$
\text { Assumption: } \bar{y}_{A}<\bar{y}_{B} \text {. }
$$

For this assumption to hold, the reservation value, $\nu$, should be greater than zero and less than $\frac{1}{12}$.

\subsection{Quality Decision under the Integrated vs. Integrated Channel Structure}

I first study the case in which both the retailers choose the integrated distribution channel structure. Let $\pi_{A}$ and $\pi_{B}$ represent the profits of Retailers $A$ and $B$, respectively:

$$
\begin{aligned}
& \pi_{A}=\left(p_{A}-q_{A}^{2}\right) \bar{y}_{A}, \\
& \pi_{B}=\left(p_{B}-q_{B}^{2}\right)\left(1-\bar{y}_{B}\right) .
\end{aligned}
$$

The retailers choose their retail prices to maximize profits, taking the equilibrium levels of quality as given. Solving the first-order conditions of profit maximization gives the price reaction functions. By substituting the price reaction functions into the profit functions, 
the equilibrium levels of quality are obtained by solving the first-order conditions of profit maximization with respect to the levels of quality.

I find the following optimal level of quality, retail prices, and retailers' profits:

$$
\begin{aligned}
& q_{A}^{*}=q_{B}^{*}=\frac{1}{6}(1+\sqrt{1-12 \nu}), \\
& p_{A}^{*}=p_{B}^{*}=\frac{1}{9}(3 \nu+\sqrt{1-12 \nu}+1), \\
& \pi_{A}^{*}=\pi_{B}^{*}=\frac{1}{36}(12 \nu+\sqrt{1-12 \nu}+1), \\
& M S_{A}^{*}=M S_{B}^{*}=\frac{1}{2} .
\end{aligned}
$$

Since the retailers first choose the distribution channel structure and then set the level of quality, they end up choosing the same level of quality and have the same resulting profit. Although I assume that the market is not covered, the market is covered by an outcome and each retailer's market share thus becomes half of the market.

\subsection{Quality Decision under the Decentralized vs. Decentralized Channel Structure}

I now consider the case in which both the retailers choose the decentralized channel. Each decentralized supplier chooses its level of quality and then its wholesale price to maximize its profits. Each retailer chooses the retail price that maximizes its profits given the levels of quality and wholesale prices. In this model, the suppliers are Stackelberg leaders. Let $\pi_{A}$ and $\pi_{B}$ represent the profits of Retailers A and B, and $\pi_{S A}$ and $\pi_{S B}$ represent the profits of Suppliers A and B, respectively:

$$
\begin{aligned}
& \pi_{A}=\left(p_{A}-w_{A}\right) \bar{y}_{A}, \\
& \pi_{B}=\left(p_{B}-w_{B}\right)\left(1-\bar{y}_{A}\right), \\
& \pi_{S A}=\left(w_{A}-q_{A}^{2}\right) \bar{y}_{A}, \\
& \pi_{S B}=\left(w_{B}-q_{B}^{2}\right)\left(1-\bar{y}_{B}\right) .
\end{aligned}
$$

Using backward induction to solve the subgame perfect equilibrium for prices and levels of quality yields the following optimal levels of quality, wholesale prices, retail prices, suppliers' profits, retailers' profits, and market shares:

$$
\begin{aligned}
& q_{A}^{*}=q_{B}^{*}=\frac{1}{6}(1+\sqrt{1-12 \nu}), \\
& w_{A}^{*}=w_{B}^{*}=\frac{1}{9}(3 \nu+\sqrt{1-12 \nu}+1), \\
& p_{A}^{*}=p_{B}^{*}=\frac{1}{36}(24 \nu+5 \sqrt{1-12 \nu}+5), \\
& \pi_{S A}^{*}=\pi_{S B}^{*}=\frac{(12 \nu+\sqrt{1-12 \nu}+1)^{2}}{108(1+\sqrt{1-12 \nu})}, \\
& \pi_{A}^{*}=\pi_{B}^{*}=\frac{(12 \nu+\sqrt{1-12 \nu}+1)^{2}}{216(1+\sqrt{1-12 \nu})}, \\
& M S_{A}^{*}=M S_{B}^{*}=\frac{1}{6}(2-\sqrt{1-12 \nu}) .
\end{aligned}
$$

\subsection{Quality Decision under the Integrated vs. Decentralized Channel Structure}

Without loss of generality, I assume that 
Retailer A chooses the integrated channel and Retailer B chooses the decentralized channel. The integrated retailer sets its retail price to maximize its profit given the level of quality. Let $\pi_{A}$ represent the profit of Retailer $\mathrm{A}$ :

$$
\pi_{A}=\left(p_{A}-q_{A}^{2}\right) \bar{y}_{A} .
$$

The decentralized retailer sets its retail price to maximize its profit given the level of quality and its wholesale price. The decentralized supplier chooses its level of quality and then sets its wholesale price to maximize its profit. Let $\pi_{B}$ and $\pi_{S B}$ represent the profits of Retailer B and Supplier B:

$$
\begin{aligned}
& \pi_{B}=\left(p_{B}-w_{B}\right)\left(1-\bar{y}_{B}\right), \\
& \pi_{S B}=\left(w_{B}-q_{B}^{2}\right)\left(1-\bar{y}_{B}\right) .
\end{aligned}
$$

Using backward induction to solve the subgame perfect equilibrium for prices and levels of quality yields the following optimal levels of quality, wholesale prices, retail prices, suppliers' profits, retailers' profits, and market shares:

$$
\begin{aligned}
& q_{A}^{*}=q_{B}^{*}=\frac{1}{6}(1+\sqrt{1-12 \nu}), \\
& w_{B}^{*}=\frac{1}{9}(3 \nu+\sqrt{1-12 \nu}+1), \\
& p_{A}^{*}=\frac{1}{9}(3 \nu+\sqrt{1-12 \nu}+1), \\
& p_{B}^{*}=\frac{1}{36}(24 \nu+5 \sqrt{1-12 \nu}+5), \\
& \pi_{S B}^{*}=\frac{(12 \nu+\sqrt{1-12 \nu}+1)^{2}}{108(1+\sqrt{1-12 \nu})},
\end{aligned}
$$

$$
\begin{aligned}
& \pi_{A}^{*}=\frac{(12 \nu+\sqrt{1-12 \nu}+1)^{2}}{54(1+\sqrt{1-12 \nu})}, \\
& \pi_{B}^{*}=\frac{(12 \nu+\sqrt{1-12 \nu}+1)^{2}}{216(1+\sqrt{1-12 \nu})}, \\
& M S_{A}^{*}=\frac{1}{3}(2-\sqrt{1-12 \nu}), \\
& M S_{B}^{*}=\frac{1}{6}(2-\sqrt{1-12 \nu}) .
\end{aligned}
$$

\subsection{Equilibrium Outcomes and Comparisons}

By using the results presented in the previous sections, I compare the equilibrium results of quality, price, and profit. The outcomes of levels of quality, retail prices, and retailers' profits under the three distribution channel structures are summarized in Table 2.

Since each retailer acts as a local monopolist in the case of the market being uncovered, the channel member decides the level of quality independently without reacting to the competitor's strategy. As a result, levels of quality are the same under any distribution channel structure. Because of double marginalization, under the decentralized channel, the retailers charge a higher retail price than under the integrated channel. Proposition 2 summarizes the results of the equilibrium channel structure decision in the simultaneous-channel-choice model under the condition of the market being uncovered.

\section{Proposition 2}

(simultaneous-channel-choice model) : 
When the consumer's reservation value, $\nu$, is sufficiently small $\left(0<\nu<\frac{1}{12}\right)$ so that the market is not covered, both the retailers simultaneously choose the integrated channel in equilibrium.

As shown in the previous section with the condition of the market being covered, an asymmetric channel structure can benefit the retailers by competing on quality differentiation and softening price competition. However, when both the retailers play the role of local monopolists under the condition of the market being uncovered, each retailer's channel efficiency has a more critical role than the role of competition between the retailers in the decision on the optimal channel structure. In a monopoly, the vertically integrated channel is optimal because of the double marginalization problem (McGuire and Staelin 1983; Moorthy 1988).
With the condition of the market being uncovered, the equilibrium is that both the retailers choose the integrated channel structure; these results are consistent with those of previous studies. Surprisingly, although I assume that the market is not covered under the condition of $0<\nu<\frac{1}{12}$, the market is covered as an outcome under the condition in which both the retailers choose an integrated channel structure. As a result, their profits under the II structure are higher than those under the DD structure because the retailers have higher channel efficiency and higher market share.

\section{Sequential Move Game: Market Is Covered}

In the previous section, I examined the

〈Table 2〉 Outcomes of Quality, Retail Prices, and Retailers' Profits under the Three Distribution Channel Structures in the Simultaneous-Channel-Choice Model (when the market is not covered, $0<\nu<\frac{1}{12}$ )

\begin{tabular}{|c|c|c|c|}
\hline Structure & Quality & Retail Price & Profit \\
\hline II & $\frac{1}{6}(1+\sqrt{1-12 \nu})$ & $\frac{1}{9}(3 \nu+\sqrt{1-12 \nu}+1)$ & $\frac{1}{36}(12 \nu+\sqrt{1-12 \nu}+1)$ \\
\hline DD & $\frac{1}{6}(1+\sqrt{1-12 \nu})$ & $\frac{1}{36}(24 \nu+5 \sqrt{1-12 \nu}+5)$ & $\frac{(12 \nu+\sqrt{1-12 \nu}+1)^{2}}{216(1+\sqrt{1-12 \nu})}$ \\
\hline \multirow{2}{*}{$\begin{array}{ll} & \text { I } \\
\text { ID } & \\
& \text { D }\end{array}$} & $\frac{1}{6}(1+\sqrt{1-12 \nu})$ & $\frac{1}{9}(3 \nu+\sqrt{1-12 \nu}+1)$ & $\frac{(12 \nu+\sqrt{1-12 \nu}+1)^{2}}{54(1+\sqrt{1-12 \nu})}$ \\
\hline & $\frac{1}{6}(1+\sqrt{1-12 \nu})$ & $\frac{1}{36}(24 \nu+5 \sqrt{1-12 \nu}+5)$ & $\frac{(12 \nu+\sqrt{1-12 \nu}+1)^{2}}{216(1+\sqrt{1-12 \nu})}$ \\
\hline
\end{tabular}


simultaneous-channel-choice model. Now, I analyze the sequential-channel-choice-model in which one retailer chooses its distribution channel structure before the other retailer. The choices of the levels of quality and prices are still simultaneous. In other words, the leaderretailer first chooses the distribution channel structure, and then the follower-retailer observes the leader-retailer's distribution channel structure and chooses its own distribution channel structure. Second, the product quality level is chosen by either the retailer in the integrated channel or the supplier in the decentralized channel. Third, the suppliers (in the case of decentralized channels) set wholesale prices $w_{i}$. Fourth, the retailers simultaneously set retail prices $p_{i}$. Fifth, consumers decide which products to purchase.

I want to understand whether a first-mover advantage exists. I assume that the consumer's reservation value, $\nu$, is sufficiently large so that all consumers buy one of the two products and thus, by definition, the market is covered. Without loss of generality, I assume that Retailer A is the leader and Retailer B is the follower in this sequential-channel-choice-model. Figure 1 presents the distribution channel choices of Retailers A and B.

In the sequential-channel-choice model, the results of the optimal levels of quality, prices, and profits are equivalent to the results obtained under the simultaneous-channel-choice model in the sense that the two retailers or suppliers choose their levels of quality and prices under a given distribution channel structure. With the sequential-channel-choice model, the outcome when both the retailers choose the integrated channel is

$$
\begin{aligned}
& q_{I I}^{*}=q_{A}^{*}=q_{B}^{*}=\frac{8}{5}, q_{I I}^{*}=q_{A}^{*}=q_{B}^{*}=\frac{65}{64}, \\
& \pi_{I I}^{*}=\pi_{A}^{*}=\pi_{B}^{*}=\frac{5}{16} .
\end{aligned}
$$

〈Figure 1〉 The Sequential-Channel-Choice Model

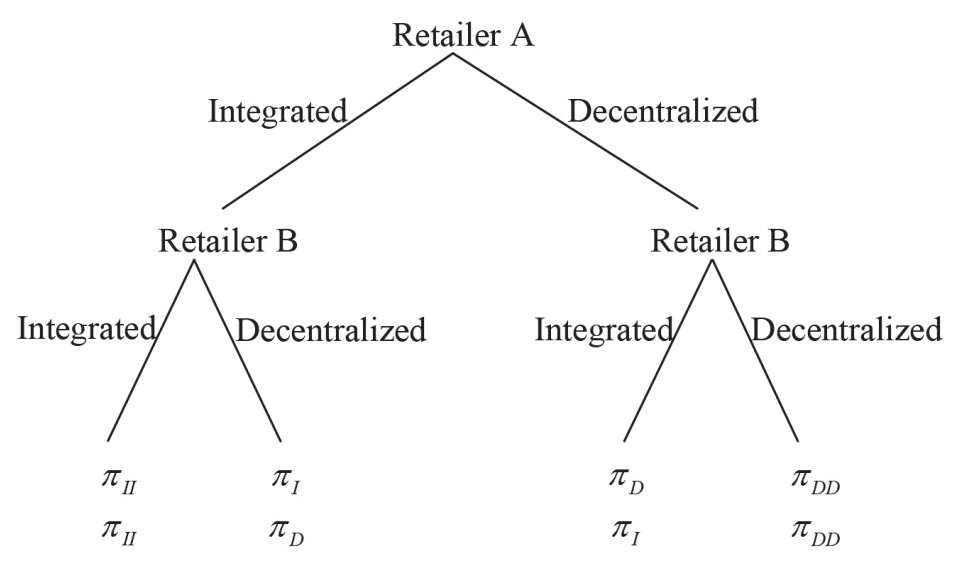

Effects of Channel Structure on the Quality Competition of Exclusively Distributed Products 51 
When both the retailers choose the decentralized channel, the outcome is

$$
\begin{aligned}
& q_{D D}^{*}=q_{A}^{*}=q_{B}^{*}=\frac{11}{8}, \\
& w_{D D}^{*}=w_{A}^{*}=w_{B}^{*}=\frac{385}{64}, \\
& p_{D D}^{*}=p_{A}^{*}=p_{B}^{*}=\frac{473}{64}, \\
& \pi_{S D D}^{*}=\pi_{S A}^{*}=\pi_{S B}^{*}=\frac{33}{16}, \\
& \pi_{D D}^{*}=\pi_{A}^{*}=\pi_{B}^{*}=\frac{11}{16} .
\end{aligned}
$$

When one retailer chooses the integrated channel structure and the other retailer chooses the decentralized channel structure, the following optimal levels of quality, wholesale prices, retail prices, suppliers' profits, and retailers' profits result:

$$
\begin{aligned}
& q_{I}^{*}=\frac{8}{5}, q_{D}^{*}=\frac{2}{5}, w_{D}^{*}=\frac{64}{25}, p_{i}^{*}=\frac{94}{25}, \\
& p_{D}^{*}=\frac{84}{25}, \pi_{I}^{*}=\frac{18}{25}, \pi_{D}^{*}=\frac{8}{25}, \pi_{S D}^{*}=\frac{24}{25}
\end{aligned}
$$

Proposition 3 summarizes the results of the equilibrium channel structure decision in the sequential-channel-choice model under the condition of the market being covered.

\section{Proposition 3}

(sequential-channel-choice model):

When the consumer's reservation value, $\nu$, is sufficiently large so that the market is covered, the leader-retailer chooses the integrated channel and the follower-retailer chooses the decentralized channel.

As shown in the previous section, there are two equilibria: one retailer chooses the integrated channel and the other retailer chooses the decentralized channel, or vice versa. In the sequential-channel-choice model, the only equilibrium outcome is that the leader chooses the integrated channel and the follower chooses the decentralized channel. This result shows that the leader can choose the distribution channel to defend itself against a future follower entrant and thus gain a first-mover advantage. In the sequential-channel-choice model, the leader-retailer is better off under the integrated channel because the leader can anticipate that the follower will choose the decentralized channel given the leader's choice of the integrated channel. The decentralized follower has higher profits than it would under the integrated channel when the leader chooses the integrated channel before the follower. Given this asymmetric channel structure, the two retailers choose different levels of quality, and this quality differentiation benefits both retailers by softening price competition.

\section{Perspective of Suppliers}

So far, I have examined the channel decision problem from the perspective of retailers, as 
retailers were the decision makers choosing the structure for their whole channel. Now, I examine the channel decision problem from the perspective of suppliers, which is equivalent to the case analyzed in McGuire and Staelin (1983).

I assume that a supplier distributes its product directly or through a retailer. In the first case, both the suppliers distribute their products directly. In this integrated case, the two suppliers choose the levels of quality and then set retail prices. In the decentralized case, the two suppliers choose the levels of quality and set the wholesale prices they charge their own retailer. Each retailer in the decentralized channel chooses the retail price to maximize its profits.

I consider the cases of the market being covered and uncovered. When the consumer's reservation value, $\nu$, is sufficiently large, all consumers buy one of the two products and the market is covered. When the consumer's reservation value, $\nu$, is sufficiently small $\left(0<\nu<\frac{1}{12}\right)$, the two channels act as local monopolists and some markets are not covered by either retailer.

I use backward induction to solve the subgame perfect equilibrium for prices and levels of quality. From the perspective of suppliers, the computation of demand functions, levels of quality, prices, and profits is consistent with the case of the perspective of retailers in the sense of the specification of demand.

I first study the case in which both the suppliers distribute their products directly. In other words, they both choose an integrated channel structure. The two suppliers set their levels of quality simultaneously to maximize their profits. Then, the two suppliers set their retail prices simultaneously to maximize their profits given the levels of quality. Backward induction yields the following levels of quality, retail prices, and suppliers' profits:

When the market is covered (when $\nu$ is sufficiently large):

$$
q_{S I I}^{*}=\frac{8}{5}, p_{S I I}^{*}=\frac{64}{65}, \pi_{S I I}^{*}=\frac{5}{16} .
$$

When the market is not covered (when $\nu$ is sufficiently small, $0<\nu<\frac{1}{12}$ ):

$$
\begin{aligned}
& q_{S I I}^{* *}=\frac{1}{6}(1+\sqrt{1-12 \nu}), \\
& p_{S I I}^{* *}=\frac{1}{9}(3 \nu+\sqrt{1-12 \nu}+1), \\
& \pi_{S I I}^{* *}=\frac{1}{36}(12 \nu+\sqrt{1-12 \nu}+1) .
\end{aligned}
$$

I now consider the case in which both the suppliers choose the decentralized channel. Under decentralized channel structures, these two suppliers set their levels of quality simultaneously to maximize their profits. Then, they both set their wholesale prices to be charged to their retailers. Both the retailers set their retail prices simultaneously to maximize their profits. Backward induction yields the 
following levels of quality, wholesale prices, retail prices, suppliers' profits, and retailers' profits:

When the market is covered (when $\nu$ is sufficiently large):

$$
\begin{aligned}
& q_{S D D}^{*}=\frac{11}{8}, w_{S D D}^{*}=\frac{385}{64}, p_{S D D}^{*}=\frac{473}{64}, \\
& \pi_{S D D}^{*}=\frac{33}{16}, \pi_{R D D}^{*}=\frac{11}{16} .
\end{aligned}
$$

When the market is not covered (when $\nu$ is sufficiently small, $0<\nu<\frac{1}{12}$ ):

$$
\begin{aligned}
q_{S D D}^{* *} & =\frac{1}{6}(1+\sqrt{1-12 \nu}), \\
w_{S D D}^{* *} & =\frac{1}{9}(3 \nu+\sqrt{1-12 \nu}+1), \\
p_{S D D}^{* *} & =\frac{1}{36}(24 \nu+5 \sqrt{1-12 \nu}+5), \\
\pi_{S D D}^{*} & =\frac{(12 \nu+\sqrt{1-12 \nu}+1)^{2}}{108(1+\sqrt{1-12 \nu})}, \\
\pi_{R D D}^{*} & =\frac{(12 \nu+\sqrt{1-12 \nu}+1)^{2}}{216(1+\sqrt{1-12 \nu})} .
\end{aligned}
$$

When one supplier chooses the integrated channel structure and the other supplier chooses the decentralized channel structure, the following levels of quality, wholesale prices, retail prices, suppliers' profits, and retailers' profits result:

When the market is covered (when $\nu$ is sufficiently large):

$$
q_{S I}^{*}=\frac{8}{5}, q_{S D}^{*}=\frac{2}{5}, w_{S D}^{*}=\frac{64}{25}, p_{S I}^{*}=\frac{94}{25},
$$

$$
\begin{aligned}
& p_{S D}^{*}=\frac{84}{25}, \pi_{S I}^{*}=\frac{18}{25}, \pi_{S D}^{*}=\frac{24}{25}, \\
& \pi_{R D}^{*}=\frac{8}{25} .
\end{aligned}
$$

When the market is not covered (when $\nu$ is sufficiently small, $0<\nu<\frac{1}{12}$ ):

$$
\begin{aligned}
& q_{S I}^{* *}=q_{S D}^{* *}=\frac{1}{6}(1+\sqrt{1-12 \nu}), \\
& w_{S D}^{* *}=\frac{1}{9}(3 \nu+\sqrt{1-12 \nu}+1),
\end{aligned}
$$

$$
\begin{aligned}
& p_{S I}^{* *}=\frac{1}{9}(3 \nu+\sqrt{1-12 \nu}+1), \\
& p_{S D}^{* *}=\frac{1}{36}(24 \nu+5 \sqrt{1-12 \nu}+5), \\
& \pi_{S I}^{* *}=\frac{(12 \nu+\sqrt{1-12 \nu}+1)^{2}}{54(1+\sqrt{1-12 \nu})}, \\
& \pi_{S D}^{* *}=\frac{(12 \nu+\sqrt{1-12 \nu}+1)^{2}}{108(1+\sqrt{1-12 \nu})}, \\
& \pi_{R D}^{* *}=\frac{(12 \nu+\sqrt{1-12 \nu}+1)^{2}}{216(1+\sqrt{1-12 \nu})} .
\end{aligned}
$$

By using the results presented in the previous sections, I now compare the optimal outcomes of quality, prices, and profits. The outcomes of levels of quality, retail prices, wholesale prices, and suppliers' profits under the three distribution channel structure types are summarized in Tables 3 and Table 4. Since each retailer acts as a local monopolist in the case of the market being uncovered, each decides the level of quality independently without reacting to the competitor's strategy. As a result, the levels of quality are the same as under any of the 
distribution channel structures in Table 2.

Proposition 4 summarizes the results of the equilibrium channel structure decision from the perspective of the supplier.

\section{Proposition 4}

(from the perspective of the supplier in a simultaneous-channel-choice model):

i) When the consumer's reservation value, $\nu$, is sufficiently large so that the market is covered, both the retailers choose the decentralized channel in equilibrium.

ii) When the consumer's reservation value, $\nu$, is sufficiently small $\left(0<\nu<\frac{1}{12}\right)$ so that the market is not covered, both the retailers choose the integrated channel in equilibrium.

When $\nu$ is sufficiently large (i.e., the market is covered), the equilibrium outcome is that

〈Table 3〉 Outcomes of Quality, Retail Prices, Wholesale Prices, and Suppliers' Profits (when the market is covered, $\nu$ is sufficiently large)

\begin{tabular}{ccccc}
\hline $\begin{array}{c}\text { Channel } \\
\text { Structure }\end{array}$ & II & DD & ID & D \\
\hline Quality & $\frac{5}{8}$ & $\frac{11}{8}$ & $\frac{8}{5}$ & $\frac{2}{5}$ \\
Wholesale Price & N/A & $\frac{385}{64}$ & N/A & $\frac{65}{64}$ \\
Retail Price & $\frac{65}{64}$ & $\frac{473}{64}$ & $\frac{94}{25}$ & $\frac{84}{25}$ \\
Profit & $\frac{5}{16}$ & $\frac{33}{16}$ & $\frac{18}{25}$ & $\frac{24}{25}$ \\
\hline
\end{tabular}

〈Table 4〉 Outcomes of Retail Prices, Wholesale Prices, and Suppliers' Profits

(when market is not covered, $0<\nu<\frac{1}{12}$ )

\begin{tabular}{|c|c|c|c|}
\hline Structure & Wholesale Price & Retail Price & Profit \\
\hline II & N/A & $\frac{1}{9}(3 \nu+\sqrt{1-12 \nu}+1)$ & $\frac{1}{36}(12 \nu+5 \sqrt{1-12 \nu}+5)$ \\
\hline DD & $\frac{1}{9}(3 \nu+\sqrt{1-12 \nu}+1)$ & $\frac{1}{36}(24 \nu+5 \sqrt{1-12 \nu}+5)$ & $\frac{(12 \nu+\sqrt{1-12 \nu}+1)^{2}}{108(1+\sqrt{1-12 \nu})}$ \\
\hline I & N/A & $\frac{1}{9}(3 \nu+\sqrt{1-12 \nu}+1)$ & $\frac{(12 \nu+\sqrt{1-12 \nu}+1)^{2}}{54(1+\sqrt{1-12 \nu})}$ \\
\hline $\mathrm{D}$ & $\frac{1}{9}(3 \nu+\sqrt{1-12 \nu}+1)$ & $\frac{1}{36}(24 \nu+5 \sqrt{1-12 \nu}+5)$ & $\frac{(12 \nu+\sqrt{1-12 \nu}+1)^{2}}{108(1+\sqrt{1-12 \nu})}$ \\
\hline
\end{tabular}


both the suppliers choose the decentralized channel. Because the suppliers are Stackelberg leaders and the market is covered, the wholesale prices and retail prices under $\mathrm{DD}$ are very high, while the level of quality is relatively low. This makes their costs relatively low and raises profits to the suppliers. When $\nu$ is sufficiently small (i.e., the market is not covered), both the suppliers are local monopolists and the equilibrium outcome is that both choose the integrated channel. Under II, these suppliers choose the same level of quality. The integrated channel generates high profits to the supplier compared with the decentralized channel because of the double marginalization problem. This result is consistent with the results of McGuire and Staelin's (1983) study. McGuire and Staelin (1983) show that when demand is independent and each firm is a monopolist, the equilibrium outcome is that each supplier will distribute its product through the vertically integrated store. When the products are strongly competitive and each supplier's demand is strongly influenced by its competitor's strategy, a supplier will be more likely to choose the decentralized channel because decentralization can have a "buffer effect" on competition and thus soften it.

\section{Conclusion}

This study examined retailers' optimal quality decisions under different distribution channel structures. I developed a game-theoretical model of duopoly and compared three channel structures: II, DD, and ID. I analyzed both simultaneous-channel-choice and sequentialchannel-choice models. Analyzing different setups helps generate a number of insights into the distribution channel decision and quality differentiation.

First, in the presence of competition in retail stores and product quality levels, retailers benefit from an asymmetric channel structure when I assume that they both choose the distribution channel structure simultaneously. Given this asymmetric channel structure, each retailer chooses a different level of quality, and this quality competition benefits them both by softening price competition. Under a Nash equilibrium, one retailer chooses the integrated channel and the other retailer chooses the decentralized channel, or vice versa. However, when both retailers serve as local monopolists, the equilibrium is that both retailers choose the integrated channel structure because of its higher channel efficiency.

Second, in the simultaneous-channel-choice model, asymmetric pairs of integrated and decentralized channel structures are two Nash equilibria. However, a first-mover advantage exists in the sequential-channel-choice model, with the leader-retailer choosing the integrated channel and the follower-retailer choosing the decentralized channel. Since a leader can anticipate 
the follower's reaction, the leader chooses the integrated channel and enjoys higher profits.

Third, these results are based on the assumption that retailers choose their distribution channel structures and that the quality decision depends on the channel selected. However, these results changed when viewed from the perspective of suppliers choosing their distribution channel structures. From this perspective, when competition on product quality and retail levels exists, the equilibrium outcome is that both suppliers choose the decentralized channel. Decentralization gives both suppliers the buffer to manage strong competition. When each channel acts as a local monopoly, the equilibrium outcome is that both suppliers choose the integrated channel, which raises channel efficiency and generates higher profits to each supplier.

Overall, the findings of this study contribute to the marketing literature in several ways. First, this study investigated the relationship between product differentiation and channel structure. Second, it presented a new advantage to decentralization when the quality decision is endogenous. Decentralization can help a retailer mitigate fierce price competition if two retailers have asymmetric distribution channel structures and differentiated levels of quality. While previous research in the area of quality decisions is mainly carried out from the perspective of manufacturers (Moorthy 1984; Villas-Boas 1998; Banker et al. 1998; Desai 2001; Netessine and Taylor 2007; Shi et al. 2013), we compare two cases in which retailers determine their quality and the producer determines its quality.

While this study adds to the growing literature of quality competition, one major limitation in this study is obviously the lack of generality. The symmetric channel structure in both II (when the two retailers are integrated) and DD (when the two retailers are decentralized) have the symmetric demand functions and the same cross effects of one retailer's quality change on the other competing retailer's demand, consequently. However, the asymmetric channel structure in ID (competition between the integrated and decentralized channels) have the asymmetric demand functions and different cross effects of one retailer's quality change on the other competing retailer's demand because their levels of qualities and prices are different as a result of competition. Further research may relax the assumptions for product quality and demand that are the limitations in this study. Moreover, big box stores like Hi-Mart, Lotte Mart and E-Mart in Korea play a dominant role in the retailing industry these days. The dominant retailers are frequently the largest distributors for manufacturers (Raju and Zhang 2005). In such a case, the dominant retailer may become a Stackelberg price leader. The optimal channel structure strategy with consideration of dominant retailers is necessary. Introducing the dominant retailers into this model would make it more realistic and new managerial insights would be obtained for channel 
and marketing managers who are charge in selecting store brand vendors.

〈Received September 14. 2017〉

〈Accepted January 28. 2018〉

\section{References}

Aaker, D. A., \& Biel, A. L. (1993). Brand equity and advertising: Advertising's role in building store brands. Lawrence Erlbaum Associates, Hills-dale, NJ.

Ailawadi, K. L., Pauwels, K., \& Steenkamp, J. E. M. (2008). Private label use and store loyalty. Journal of Marketing, 72, 19-30.

Banker, R. D., Khosla, I., \& Sinha, K. K. (1998). Quality and competition. Management Science, 44(9), 1179-1192.

Binninger, A-S. (2008). Exploring the relationships between retail brands and consumer store loyalty. International Journal of Retail and Distribution Management, 36(2), 94-110.

Bonfrer, A., \& Chintagunta, P. K. (2004). Store brands: Who buys them and what happens to retail prices when they are introduced? Review of Industrial Organization, 24, 195218.

Burritt, C. (2012). Best Buy CEO Hubert Joly considers buying electronics brands. Businessweek.com, November 14.

Collins-Dodd, C., \& Lindley, T. (2003). Store brands and retail differentiation: The influence of store image and store brand attitude on store own brand perceptions. Journal of Retailing and Consumer Services, 10, 345-352.

Corstjens, M., \& Lal, R. (2000). Building store loyalty through store brands. Journal of Marketing Research, 37(August), 281-291. Coughlan, A. T. (1985). Competition and cooperation in marketing channel choice: Theory and application. Marketing Science, $4(2), 110-129$.

Coughlan, A. T., \& Wernerfelt, B. (1988). Credible delegation by oligopolists: A discussion of distribution channel management. Management Science, 35(2), 226-239.

Desai, P. (2001). Quality segmentation in spatial markets: When does cannibalization affect product line design? Marketing Science, 20(3), 265-283.

Gielens, K., Gijsbrechts, E., \& Dekimpe, M.G. (2014). Gains and losses of exclusivity in grocery retailing. International Journal of Research in Marketing, 31, 239-252.

Gonzalez-Benito, O., \& Martos-Partal, M. (2012). Role of retailer positioning and product category on the relationship between store brand consumption and store loyalty. Journal of Retailing, 88(2), 236-249.

Liu, Y., \& Tyagi, R. K. (2009). The Benefits of upward channel decentralization. Management Science, 57(4), 741-751.

McGuire, T. W., \& Staelin, R. (1983). An industry equilibrium analysis of downstream 
vertical integration. Marketing Science, 2 (2), 161-191.

Moorthy, K. S. (1984). Market segmentation, self-selection, and product line design. Marketing Science, 3(4), 288-307.

Moorthy, K. S. (1988). Strategic decentralization in channels. Marketing Science, 7(4), 335355.

Netessine, S., \& Taylor, T.A. (2007). Product line design and production technology. Marketing Science, 26(1), 101-117.

Peres, R., \& Van den Bulte, C. (2014). When to take or forgo new product exclusivity: Balancing protection from competition against word-of-mouth spillover. Journal of Marketing, 78, 83-100.

Shi, H., Liu, Y., \& Petruzzi, N. C. (2013). Consumer heterogeneity, product quality, and distribution channels. Management Science, 59(5), 1162-1176.

Steenkamp, J. E. M., \& Dekimpe, M. G. (1997). The increasing power of store brands:
Building loyalty and market share. Long Range Planning, 30(6), 917-930.

Trivedi, M. (1998). Distribution channels: An extension of exclusive retailership. Management Science, 44(7), 896-909.

Villas-Boas, J. M. (1998). Product line design for a distribution channel. Marketing Science, 17(2), 156-169.

Raju, J. S., and Z. J. Zhang (2005), "Channel Coordination in the Presence of a Dominant Retailer," Marketing Science, 24(2), 254262.

Raju, J. S., Srinivasan, V., \& Lal, R. (1990). The effects of brand loyalty on competitive price promotional strategies. Management Science, 36(3), 276-304.

Zhao, X., Atkins, D., \& Liu, Y. (2009). Effects of distribution channel structure in markets with vertically differentiated products. Quantitative Marketing and Economics, 7, 377-397. 